\title{
Improved power quality buck boost converter for SMPS
}

\author{
J. Jayachandran, S. Malathi \\ Department of Electrical and Electronics Engineering, SASTRA Deemed University, Thanjavur 613402, India
}

\begin{tabular}{l} 
Article Info \\
\hline Article history: \\
Received Apr 10, 2018 \\
Revised Jun 22, 2018 \\
Accepted Jul 11, 2018 \\
\hline
\end{tabular}

\section{Keywords:}

Buck-boost converter

Neural network

Power factor

Total harmonic distortion

\begin{abstract}
In this paper, a Neural Network (NN) controlled Buck-Boost Converter (BBC) based Switched Mode Power Supply (SMPS) for a PC application is proposed. The proposed BBC is analyzed, modeled and designed for the rated load. Generally, the utilization of Multiple Output SMPS (MOSMPS) for PC application introduces Power Quality (PQ) issues in the power system network. Unlike conventional SMPS the proposed NN controlled BBC can accomplish improvement of power quality. The NN controller reduces the Total Harmonic Distortion (THD) of source current below 5\%, maintains input side Power Factor (PF) to be nearly unity and improves the output voltage regulation. In the proposed system, $\mathrm{NN}$ controller replaces the conventional PI controller and overcomes the drawbacks of the conventional system. The proposed BBC is validated adopting MATLAB/SIMULINK software. The simulation analysis validate that the proposed $\mathrm{NN}$ controlled $\mathrm{BBC}$ performs better than conventional converter in terms of PQ indices under fluctuating conditions.
\end{abstract}

Copyright $\odot 2019$ Institute of Advanced Engineering and Science. All rights reserved.

\section{Corresponding Author:}

J. Jayachandran,

Departement of Electrical and Electronics Engineering,

SASTRA Deemed University,

Thirumalaisamudram, Thanjavur, Tamil Nadu 613401, India.

Email: jj_chandru@eee.sastra.edu

\section{INTRODUCTION}

At present Electronic gadgets like Personal Computer (PC), Laptop, mobile, etc., play a major role in human life. But these gadgets introduce harmonics in the distribution system which pollutes and degrades the PQ of the electric supply system. SMPS supplies multiple DC output voltages to various accessories like mouse, keyboard, touch pad etc., in PC application. These SMPS draw highly distorted sinusoidal current from input ac mains and thereby increase the THD of source current, reduce the PF at the source side and decrease the overall performance of the system. Based on the literature survey, the conventional SMPS has THD of the source current about $81.2 \%$ and PF around 0.4 [1]. Thus the conventional SMPS violates the IEC and IEEE-519 standards of PQ [2]. Single stage SMPS is preferred in many PC applications for PQ improvement and power conversion. But it suffers from major drawbacks like increased stress across the switch and degradation of output voltage. To improve the performance of the single stage SMPS, PFC converters are implemented in the front stage which improve the PF and PQ. The buck and boost converters are not preferred for PC application where the input ac main voltage varies from $170 \mathrm{~V}$ to $270 \mathrm{~V}$. For an ac voltage of $230 \mathrm{~V}$, the output of the uncontrolled bridge rectifier is about $320 \mathrm{~V}$ and thus the boost and buck converter cannot control the output voltage below 350V. To overcome the above deficiency, $\mathrm{BBC}$ is preferred for PC application which can operate with a nominal ac voltage of $220 \mathrm{~V}$ and improve the PQ with a Diode Bridge Rectifier (DBR) at front end [3], [4].

The Power Factor Correction (PFC) converters are operated in two different modes of operation i.e., a) Discontinuous conduction mode (DCM) and b) Continuous Conduction Mode (CCM). The DCM of operation is preferred in PFC converters since it reduces the size of the inductor. The BBC with different configurations and two switches is proposed by chen et al [4]. A. Abramovitz et al [5] designed a BB 
converter configuration which mitigates the sudden inrush currents, protects against short circuit and improves PQ for a wide variation of ac main voltages. In [6], various bridgeless BB converter topologies are analyzed and in [7] higher order low power BB converter is analyzed for continuous current but the number of component required is high in both analysis when compared to conventional one. Hence the selection of converter is a trade-off between the source current waveform and number of components. In SMPS application, to have minimum switching stress, improved utilization of core and lesser voltage ripple at the output a half bridge Voltage Source Inverter (VSI) is preferred [8]-[12]. This paper deals with NN based SMPS having an ac-dc converter at the front end to improve the PQ in terms of THD and PF and with tight voltage regulation at the output for wide variation of source and load conditions.

\section{PROPOSED NN CONTROLLED CONVERTER FOR SMPS}

\subsection{Design of buck boost converter}

Figure 1 shows the SMPS with PFC buck-boost converter at the front end and an isolated Half Bridge (HB) converter for multiple isolated output voltages. The input AC supply is rectified into uncontrolled DC voltage with the help of DBR. The output of DBR is fed to the LC filter and then to buck-boost converter to obtain controlled DC voltage. The controlled DC voltage is applied to HBVSI. The capacitors at the front end of the HBVSI perform the function of filter and help to avoid the need for an additional capacitor in the PFC converter.

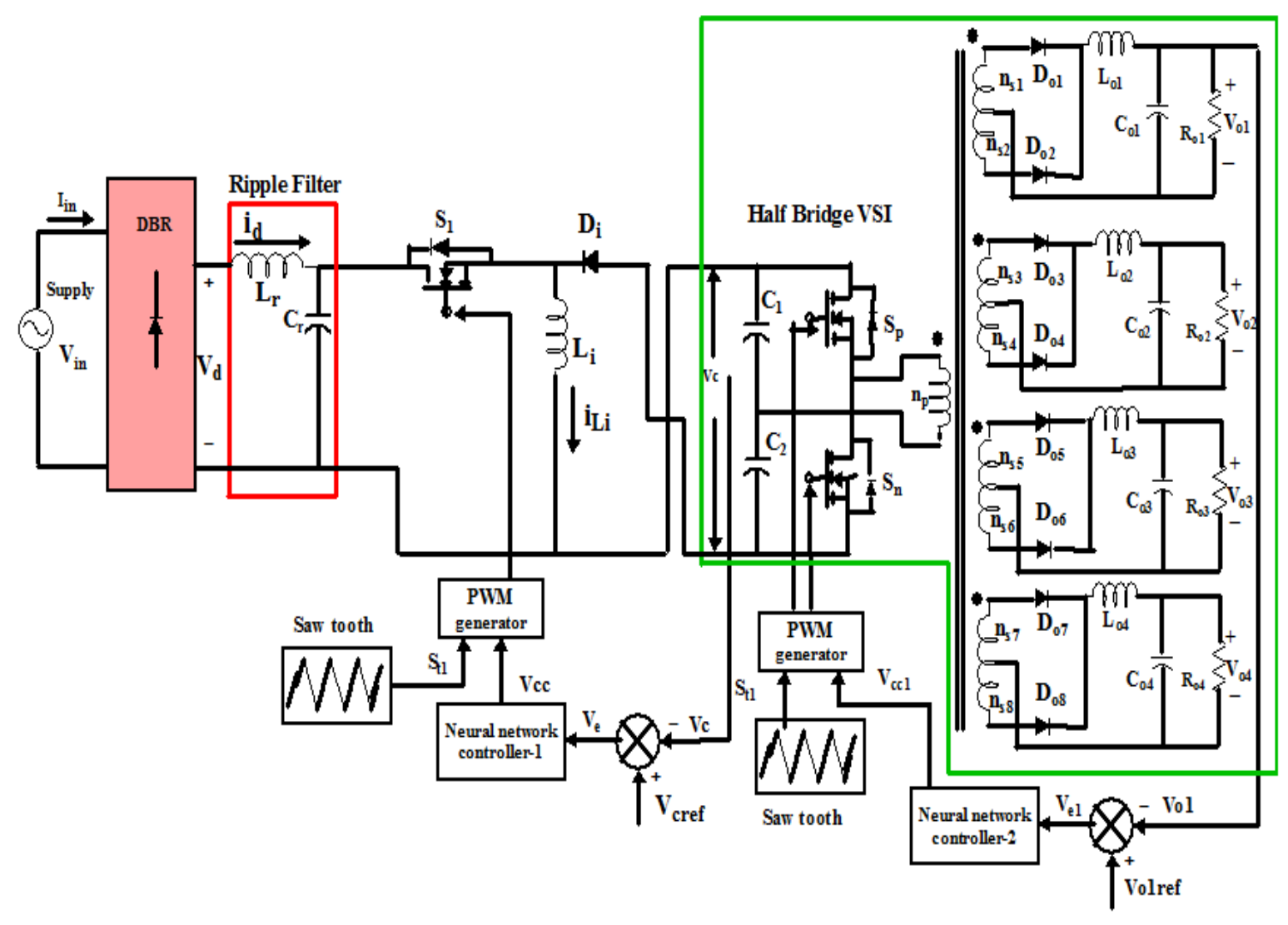

Figure 1. Circuit configuration of two-stage MOSMPS employing buck-boost PFC converter

The analysis of the proposed converter is carried out to model the converter and to determine the rating of different components by deriving the design Equations [13]. The input side PF correction can be attained by proper selection of the inductor and operating it under DCM [13].

a) Selection of inductor

The ripple content of inductor current is assumed to be two times of the input current. 


$$
\Delta i_{L i}=2 * I_{d}
$$

The value of the inductor during the $\mathrm{ON}$ state of the switch $\mathrm{S}_{1}$ can be calculated as:

$$
L_{i}=\frac{D T_{S} V_{d}}{\Delta i_{L i}}
$$

where, $\Delta \mathrm{i}_{\mathrm{Li}}=$ inductor current ripple, $\mathrm{V}_{\mathrm{d}}=$ unregulated $\mathrm{DC}$ output voltage of $\mathrm{DBR}, \mathrm{D}=$ duty cycle and $\mathrm{T}_{\mathrm{s}}=$ switching time. Substituting (2) in (1), the $\mathrm{L}_{\mathrm{imin}}$ is calculated as:

$$
L_{i \min }=\frac{D T_{S} V_{d}}{2 I_{d}}
$$

To operate the inductor under DCM for all varying source and load conditions, the value of inductor is chosen less than $0.1 * \mathrm{~L}_{\mathrm{i} \text { min }}$. Considering the switching time as $50 \mu \mathrm{s}, \mathrm{I}_{\mathrm{d}}$ as $0.88 \mathrm{~A}$, duty cycle as 0.3 and the DBR average output voltage as $198 \mathrm{~V}$, the inductor value is calculated as $1.687 \mathrm{mH}$ using Equation (3). The inductor value is selected as $160 \mu \mathrm{H}$.

b) Selection of ripple filter

The higher order harmonics present in the input current are filtered out using a second order lowpass filter that helps in the reduction of the THD of the supply current. The capacitance value for ripple filter $\left(C_{r}\right)$ is calculated using Equation (4) and is selected as $200 \mathrm{nF}$.

$$
C_{r \max }=\frac{I_{m} \tan \theta}{2 \pi f V_{m}}
$$

where, $\mathrm{V}_{\mathrm{m}}=$ maximum value of the supply voltage $=311 \mathrm{~V}, \mathrm{I}_{\mathrm{m}}=$ maximum value of input current $=\sqrt{2} *$ $0.88 \mathrm{~A}$ and $\mathrm{f}=$ supply frequency $=50 \mathrm{~Hz}$. The THD of the input supply current can be effectively reduced by proper selection of filter inductor value. The $\mathrm{L}_{\mathrm{r}}$ value is designed using the Equation (5).

$$
L_{r}=\frac{1}{4 \pi^{2} f_{c}^{2} c_{r}}
$$

Considering the cut-off frequency $\mathrm{f}_{\mathrm{c}}$ as $5 \mathrm{kHz}$, the inductor value is calculated as $5.07 \mathrm{mH}$.

\subsection{Design of half bridge converter (HBC)}

The regulated output voltage of the first stage forms the source for the HBC. Multiple output voltages are provided by a High Frequency Transformer (HFT) with centre tapped secondary windings. The inductors $\left(\mathrm{L}_{\mathrm{o} 1}-\mathrm{L}_{\mathrm{o} 4}\right)$ and capacitors $\left(\mathrm{C}_{\mathrm{o} 1}-\mathrm{C}_{\mathrm{o} 4}\right)$ connected in the secondary side of HFT are utilized for filtering current and voltage ripples. ANN controller-2 is implemented for the output voltage regulation. The highest rated secondary winding voltage is sensed for voltage control and the duty cycle is altered to control all other output voltages.

a) Selection of capacitor

In $\mathrm{HBC}$ the value of the capacitors are chosen to eliminate the $100 \mathrm{~Hz}$ ripple that is reflected from the AC input side. The PF should be maintained unity at the input side. The capacitor value is calculated using Equation (6) [13]

$$
C=\frac{I_{0}}{2 \omega \Delta V_{c}}
$$

Considering $\omega=314 \mathrm{rad} / \mathrm{sec}, \Delta \mathrm{V}_{\mathrm{c}}=6 \mathrm{~V}(2 \%)$ and $\mathrm{I}_{0}=0.58 \mathrm{~A}$, the value of $\mathrm{C}_{1}=\mathrm{C}_{2}=0.310 \mathrm{mF}$.

The proposed SMPS is modelled for PC power supply application, the capacitor value is designed so that the SMPS can withstand power failure at least for some time.

$$
C_{12}=\frac{\left(T_{\text {with }- \text { stand }}\right)\left(2 P_{0}\right)}{\left(V_{c m}^{2}-V_{c m i n}^{2}\right)}
$$

Considering $\mathrm{T}_{\text {with-stand }}=$ with-stand time of capacitor during power failure as $12 \mathrm{~ms}, \mathrm{~V}_{\mathrm{cm}}=$ minimum output DC voltage of the PFC converter $=294 \mathrm{~V}, \mathrm{~V}_{\mathrm{cmin}}=$ minimum voltage at which the output is held regulated $=260 \mathrm{~V}$ and $\mathrm{P}_{\mathrm{o}}=$ output power $=175 \mathrm{~W}$, the capacitor value is calculated using Equation (7) as $\mathrm{C}_{12}=0.22 \mathrm{mF}$. Two series connected capacitors $\mathrm{C}_{1}=\mathrm{C}_{2}=0.44 \mathrm{mF}$. 
b) Selection of inductor

The inductance value at the secondary side of the HFT is estimated using Equation (8) by assuming $\mathrm{D}=0.4, \mathrm{f}_{\mathrm{s}}=60 \mathrm{kHz}$ and $\Delta \mathrm{i}_{\mathrm{L} 01}=2 \%$ of $6 \mathrm{~A}$.

$$
L_{01}=\frac{V_{01}(0.5-D)}{f_{S} \Delta i_{L 01}}
$$

The inductor value $\left(\mathrm{L}_{01}\right)$ is calculated as $0.12 \mathrm{mH}$. The value of inductors $\mathrm{L}_{02}, \mathrm{~L}_{03}$ and $\mathrm{L}_{04}$ in the secondary windings of the HFT are calculated using Equation (8) as $\mathrm{L}_{02}=0.023 \mathrm{mH}, \mathrm{L}_{03}=1.3 \mathrm{mH}$ and $\mathrm{L}_{04}=1.25 \mathrm{mH}$.

c) Selection of turns ratio

In steady state, the current variation in the output inductor $\left(i_{\mathrm{Lo} 1}\right)$ during the switching condition is equated to zero [13] as shown below:

$$
\frac{T_{h}\left(0.5 n V_{C}-V_{01}\right) D_{h}}{L_{O 1}}+\frac{T_{h}\left(0.5-D_{h}\right) V_{01}}{L_{O 1}}=0
$$

The turns ratios are calculated by substituting the highest rated output voltage $\mathrm{V}_{01}=+12 \mathrm{~V}$, switching time of $H B C T_{h}$ and duty ratio of $H B C D_{h}=0.4$. On solving Equation (9) the turns ratio are calculated as $n_{1}=0.1$, $\mathrm{n}_{2}=0.042, \mathrm{n}_{3}=0.042$ and $\mathrm{n}_{4}=0.1$ for the secondary windings with voltage ratings $\mathrm{V}_{01}=12 \mathrm{~V}, \mathrm{~V}_{02}=5 \mathrm{~V}$, $\mathrm{V}_{03}=-5 \mathrm{~V}$ and $\mathrm{V}_{04}=-12 \mathrm{~V}$ respectively.

\subsection{Modelling of $\mathrm{BB}$ converter}

DC voltage gain and AC small-signal Transfer Function (TF) of the BBC are derived. The Average State-Space Equations (ASSE) of BBC is derived under DCM operation [14]. Under DCM operation, the BB converter has three switching stages per cycle. The DC resistance of inductor $\left(\mathrm{r}_{\mathrm{L}}\right)$ and capacitor $\left(\mathrm{r}_{\mathrm{C}}\right)$ are included in the analysis. Vector $x$ is formulated as $\left[i_{L}, v_{C}\right]$.

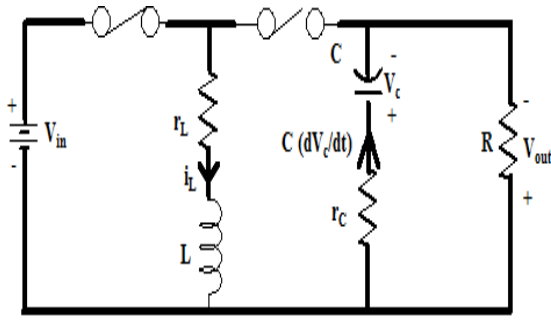

(a)

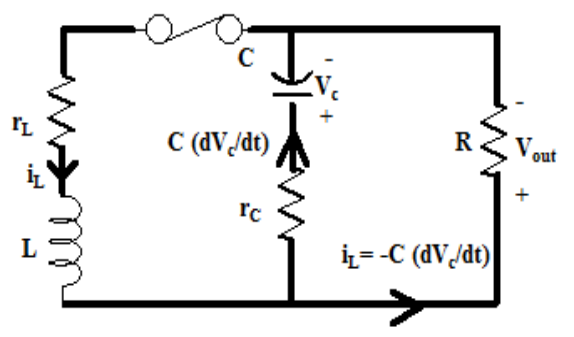

(b)

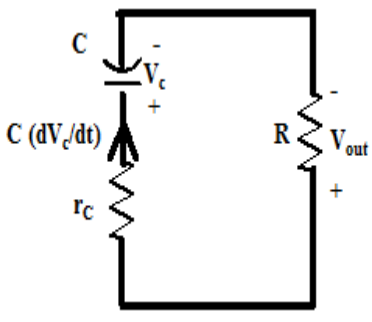

(c)

Figure 2. Modes of BBC in DCM

Figure 2(a) to Figure 2(c) represent the modes of the BBC in DCM operation. In Switching state I the State space equations are:

$$
\begin{aligned}
& \frac{\mathrm{d}}{\mathrm{dt}}\left[\begin{array}{l}
i_{L} \\
v_{C}
\end{array}\right]=\left[\begin{array}{cc}
-\frac{r_{L}}{L} & 0 \\
0 & -\frac{1}{C\left(R+r_{C}\right)}
\end{array}\right]\left[\begin{array}{l}
i_{L}(t) \\
v_{C}(t)
\end{array}\right]+\left[\begin{array}{l}
\frac{1}{L} \\
0
\end{array}\right] v_{\text {in }} \\
& v_{\text {out }}=-R\left(-\frac{v_{C}}{\left(R+r_{C}\right)}\right)=\left[\begin{array}{ll}
0 & \frac{R}{R+r_{C}}
\end{array}\right]\left[\begin{array}{c}
i_{L}(t) \\
v_{C}(t)
\end{array}\right]
\end{aligned}
$$

From the Equations (10) and (11) the values of $\mathrm{A}_{1}, \mathrm{~B}_{1}$ and $\mathrm{C}_{1}$ are derived as:

$$
\mathrm{A}_{1}=\left[\begin{array}{cc}
-\frac{r_{L}}{L} & 0 \\
0 & -\frac{1}{C\left(R+r_{C}\right)}
\end{array}\right] ; \mathrm{B}_{1}=\left[\begin{array}{c}
\frac{1}{L} \\
0
\end{array}\right] ; \mathrm{C}_{1}=\left[\begin{array}{cc}
0 & \frac{R}{R+r_{C}}
\end{array}\right]
$$


In Switching state II the State space equations are:

$$
\begin{aligned}
& \frac{\mathrm{d}}{\mathrm{dt}}\left[\begin{array}{l}
i_{L} \\
v_{C}
\end{array}\right]=\left[\begin{array}{cc}
-\frac{r_{L}+\frac{R r_{C}}{R+r_{C}}}{L} & -\frac{R}{L\left(R+r_{C}\right)} \\
\frac{R}{C\left(R+r_{C}\right)} & -\frac{1}{C\left(R+r_{C}\right)}
\end{array}\right]\left[\begin{array}{c}
i_{L}(t) \\
v_{C}(t)
\end{array}\right]+\left[\begin{array}{l}
0 \\
0
\end{array}\right] v_{\text {in }} \\
& v_{\text {out }}=\left[\begin{array}{ll}
\frac{R r_{C}}{R+r_{C}} & \frac{R}{R+r_{C}}
\end{array}\right]\left[\begin{array}{c}
i_{L}(t) \\
v_{C}(t)
\end{array}\right]
\end{aligned}
$$

From Equations (13) and (14) the values of $A_{2}, B_{2}$ and $C_{2}$ are derived as:

$$
\mathrm{A}_{2}=\left[\begin{array}{cc}
-\frac{r_{L}+\frac{R r_{C}}{R+r_{C}}}{L} & -\frac{R}{L\left(R+r_{C}\right)} \\
\frac{R}{C\left(R+r_{C}\right)} & -\frac{1}{C\left(R+r_{C}\right)}
\end{array}\right] ; \mathrm{B}_{2}=\left[\begin{array}{l}
0 \\
0
\end{array}\right] ; \mathrm{C}_{2}=\left[\begin{array}{ll}
\frac{R r_{C}}{R+r_{C}} & \frac{R}{R+r_{C}}
\end{array}\right]
$$

In switching state III the State space equations are:

$$
\begin{aligned}
& \frac{\mathrm{d}}{\mathrm{dt}}\left[\begin{array}{l}
i_{L} \\
v_{C}
\end{array}\right]=\left[\begin{array}{ll}
0 & 0 \\
0 & -\frac{1}{C\left(R+r_{C}\right)}
\end{array}\right]\left[\begin{array}{l}
i_{L}(t) \\
v_{C}(t)
\end{array}\right]+\left[\begin{array}{l}
0 \\
0
\end{array}\right] v_{\text {in }} \\
& v_{\text {out }}=-R\left(-\frac{v_{C}}{\left(R+r_{C}\right)}\right)=\left[\begin{array}{ll}
0 & \frac{R}{R+r_{C}}
\end{array}\right]\left[\begin{array}{l}
i_{L}(t) \\
v_{C}(t)
\end{array}\right]
\end{aligned}
$$

From Equations (16) and (17) the values of $A_{3}, B_{3}$ and $C_{3}$ are derived as [14]:

$$
\mathrm{A}_{3}=\left[\begin{array}{cc}
0 & 0 \\
0 & -\frac{1}{C\left(R+r_{C}\right)}
\end{array}\right] ; \mathrm{B}_{3}=\left[\begin{array}{l}
0 \\
0
\end{array}\right] ; \mathrm{C}_{3}=\left[\begin{array}{cc}
0 & \frac{R}{R+r_{C}}
\end{array}\right]
$$

The ASSE of a BBC operating under DCM can be written as [14]:

$$
\begin{aligned}
& \dot{x}=A_{a v} x(t)+B_{a v} v_{i n} \\
& v_{\text {out }}=C_{a v} x(t)
\end{aligned}
$$

where,

$$
\begin{aligned}
& A_{a v}=A_{1} d+A_{2} d_{2}+A_{3} d_{3} \\
& B_{a v}=B_{1} d+B_{2} d_{2}+B_{3} d_{3} \\
& C_{a v}=C_{1} d+C_{2} d_{2}+C_{3} d_{3}
\end{aligned}
$$

The duration of the three switching states of the converter are represented as $d T s, d_{2} T s$ and $d_{3}$ Ts respectively. The condition to be satisfied during switching operation is $\left(d+d_{2}+d_{3}=1\right)$. The analysis can be made simple by neglecting the $\mathrm{DC}$ resistance of the switches and the passive elements.Assuming $r_{L}$ and $r_{C}$ as zero, the matrices $A_{1}, B_{1}, A_{2}, B_{2}, A_{3}$ and $B_{3}$ can be re-written as [14]:

$$
\mathrm{A}_{1}=\left[\begin{array}{cc}
0 & 0 \\
0 & -\frac{1}{C R}
\end{array}\right] ; \mathrm{B}_{1}=\left[\begin{array}{l}
\frac{1}{L} \\
0
\end{array}\right] ; \mathrm{A}_{2}=\left[\begin{array}{cc}
0 & -\frac{1}{L} \\
\frac{1}{C} & -\frac{1}{C R}
\end{array}\right] ; \mathrm{B}_{2}=\left[\begin{array}{l}
0 \\
0
\end{array}\right] ; \mathrm{A}_{3}=\left[\begin{array}{cc}
0 & 0 \\
0 & -\frac{1}{C R}
\end{array}\right] ; \mathrm{B}_{2}=\left[\begin{array}{l}
0 \\
0
\end{array}\right]
$$

From Equations (28) to (31), the matrices $\mathrm{A}_{\mathrm{av}}$ and $\mathrm{B}_{\mathrm{av}}$ are calculated as:

$$
A_{a v}=\left[\begin{array}{cc}
0 & -\frac{d_{2}}{L} \\
\frac{d_{2}}{C} & -\frac{1}{C R}
\end{array}\right] ; B_{a v}=\left[\begin{array}{l}
\frac{d}{L} \\
0
\end{array}\right]
$$


The ASSE for the BB converter are written as:

$$
\begin{aligned}
& \frac{d i_{L}}{d t}=-\frac{d_{2}}{L} v_{C}+\frac{d}{L} v_{i n} \\
& \frac{d v_{C}}{d t}=\frac{d_{2}}{C\left(d+d_{2}\right)} i_{L}-\frac{1}{R C} v_{C}
\end{aligned}
$$

The average of $i_{L}(t)$ is derived as:

$$
i_{L}(t) \text { average }=\frac{1}{T_{S}} \int_{0}^{T_{S}} i_{L}(t) d t=\left(d+d_{2}\right) \frac{v_{\text {in }} d T_{S}}{2 L}
$$

The open loop small-signal TF of a BBC in DCM are:

$$
\begin{aligned}
& G_{v g}(s)=\left.\frac{\widehat{V_{\text {out }}}(s)}{\widehat{V_{\text {ln }}}(s)}\right|_{d=0}=\frac{2 M}{s R C+2} \\
& G_{v d}(s)=\left.\frac{\widehat{V_{\text {out }}}(s)}{\widehat{D}(s)}\right|_{d=0}=\frac{\frac{2}{M \sqrt{K}} V_{\text {out }}}{s R C+2}
\end{aligned}
$$

The Equations (27) and (28) are I order TF with a pole on the left-half of the s-plane.

\section{DISCUSSION ON SIMULATION ANALYSIS}

MATLAB/SIMULINK software is adopted to analyse the performance of the NN controlled BBC based MOSMPS. It is designed, modelled and simulated as per the specifications listed in Table 1. An AC source of $170 \mathrm{~V}$ to $250 \mathrm{~V} \mathrm{RMS}$ and $50 \mathrm{~Hz}$ frequency is utilized to feed the MOSMPS. Two NN controllers are employed individually for improving the input power quality and regulation of the output voltage. The simulation of the NN based MOSMPS is carried out to highlight its performance under i) steady state condition with rated load and rated supply voltage condition ii) variable supply voltage by varying the supply voltage between $170 \mathrm{~V}$ and $250 \mathrm{~V}$ RMS and iii) varying load conditions where the load at the output terminal 2 is increased from $50 \%$ to $100 \%$ at $0.5 \mathrm{~s}$ during the simulation period. The MOSMPS with NN controller and conventional controller are compared based on PQ indices and voltage regulation.

\section{Table 1. Parameters of MOSMPS}

\begin{tabular}{lc}
\hline \multicolumn{1}{c}{ Parameters } & Values \\
\hline Source voltage $\mathrm{V}_{\mathrm{in}}$ & $170-250 \mathrm{~V} \mathrm{RMS}$ \\
Rating of output terminal $1 \mathrm{~V}_{01} / \mathrm{I}_{01}$ & $12 \mathrm{~V} / 6 \mathrm{~A}$ \\
Rating of output terminal $2 \mathrm{~V}_{02} / \mathrm{I}_{02}$ & $5 \mathrm{~V} / 18 \mathrm{~A}$ \\
Rating of output terminal $3 \mathrm{~V}_{03} / \mathrm{I}_{03}$ & $-5 \mathrm{~V} / 0.3 \mathrm{~A}$ \\
Rating of output terminal $4 \mathrm{~V}_{04} / \mathrm{I}_{04}$ & $-12 \mathrm{~V} / 0.8 \mathrm{~A}$ \\
Rating of output power $\mathrm{P}_{0}$ & $175 \mathrm{~W}$ \\
\hline
\end{tabular}

\subsection{MOSMPS with rated supply voltage $\mathrm{Vin}=220 \mathrm{~V}$ and rated load}

The waveforms of regulated multiple output voltages, output currents, supply voltage and current at $V_{\text {in }}=220 \mathrm{~V}$ are depicted in Figure 3. It is concluded from the waveforms that $V_{o 1}$ to $V_{04}$ are regulated well by the NN controller. $V_{\text {in }}$ and $I_{\text {in }}$ waveforms prove that supply current drawn is maintained sinusoidal and in phase with the source voltage to maintain the PF nearly unity. The values of DF, DPF and PF achieved with NN controller are $0.996,1$ and 0.996 respectively. The THD of $\mathrm{I}_{\text {in }}$ is $2.35 \%$ and adheres to the limit suggested by IEC 61000-3-2 standard. BBC based SMPS when simulated with conventional controller, reduces the THD of the source current to $5.1 \%$ and the PF at the supply side is maintained at 0.94 . 


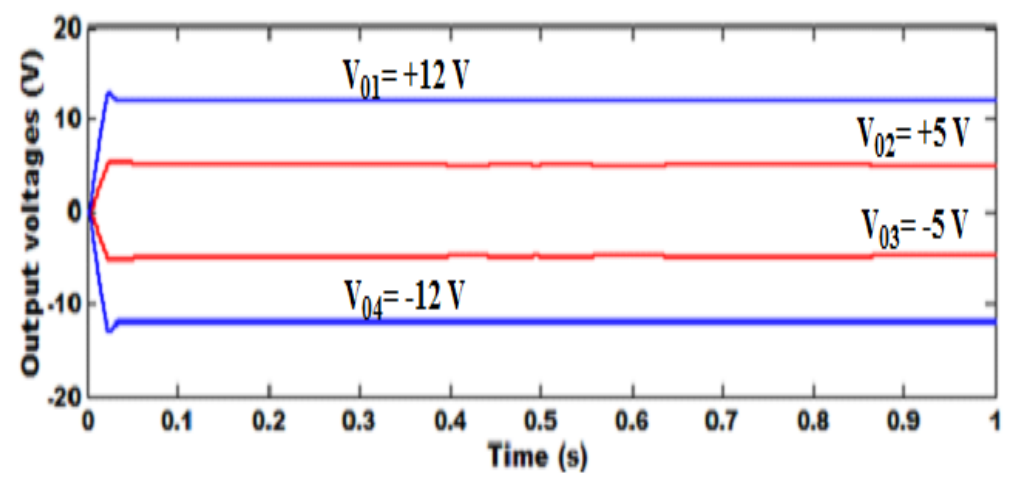

(a)

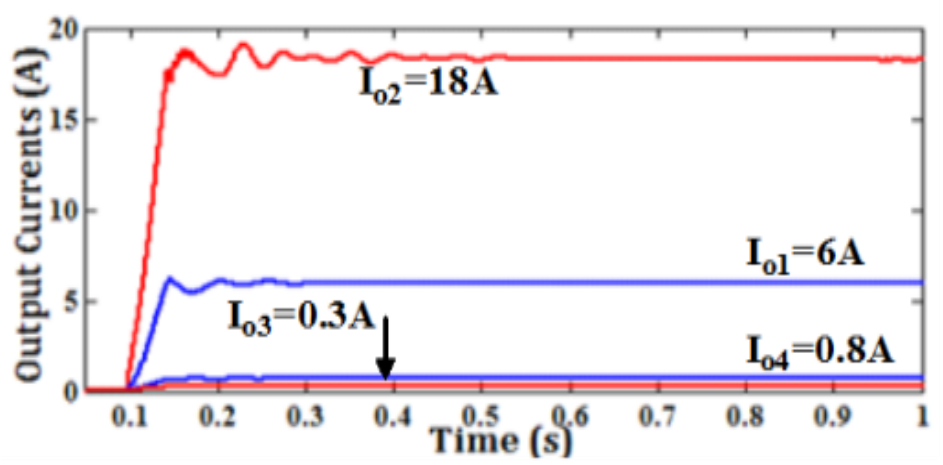

(b)

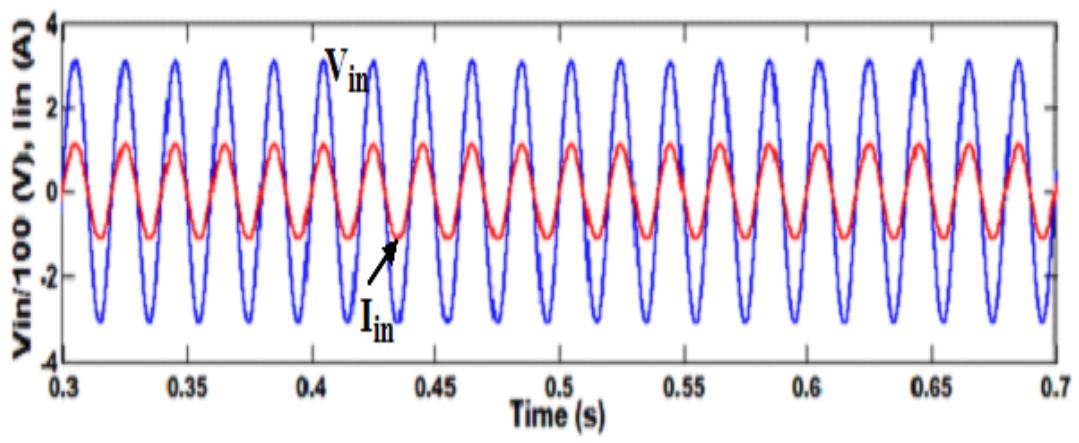

(c)

Figure 3. Waveforms of BBC at rated supply voltage. (a) $V_{01}-V_{04}(V)$, (b) $I_{01}-I_{04}$ (A) and (c) $V_{\text {in }} / 100$ (V) and $\mathrm{I}_{\text {in }}(\mathrm{A})$

\subsection{MOSMPS with increased supply voltage $\mathrm{Vin}=250 \mathrm{~V}$ and rated load}

The waveforms of regulated multiple output voltages, output currents, supply voltage and current at $\mathrm{V}_{\text {in }}=250 \mathrm{~V}$ are depicted in Figure 4 . It is concluded from the waveforms that $\mathrm{V}_{\mathrm{o} 1}$ to $\mathrm{V}_{\mathrm{o} 4}$ are regulated well by the $\mathrm{NN}$ controller. $\mathrm{V}_{\text {in }}$ and $\mathrm{I}_{\text {in }}$ waveforms prove that supply current drawn is maintained sinusoidal and in phase with the source voltage to maintain the PF nearly unity. The values of DF, DPF and PF achieved with NN controller are $0.995,1$ and 0.995 respectively. The THD of $\mathrm{I}_{\text {in }}$ is $3.42 \%$ and adheres to the limit suggested by IEC 61000-3-2 standard. BBC based SMPS when simulated with conventional controller, reduces the THD of the source current to $5.4 \%$ and the PF at the supply side is maintained at 0.9 . 


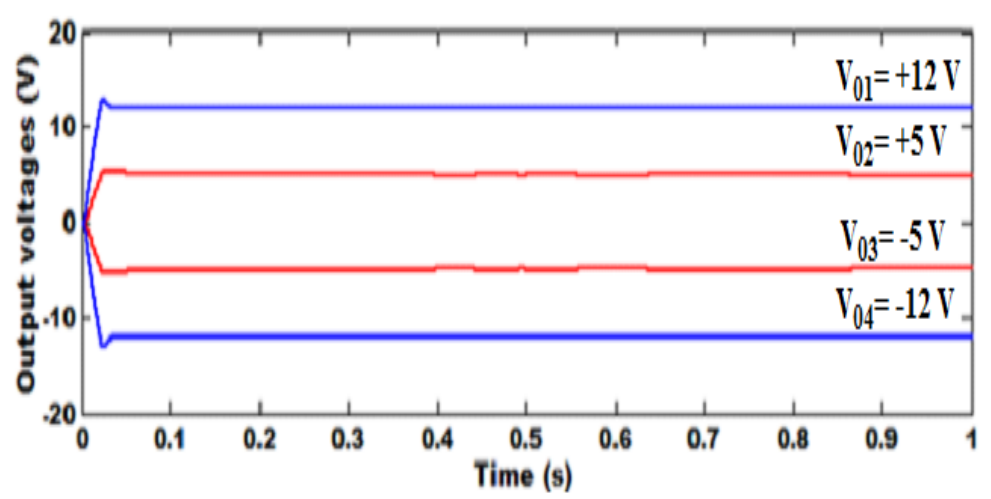

(a)

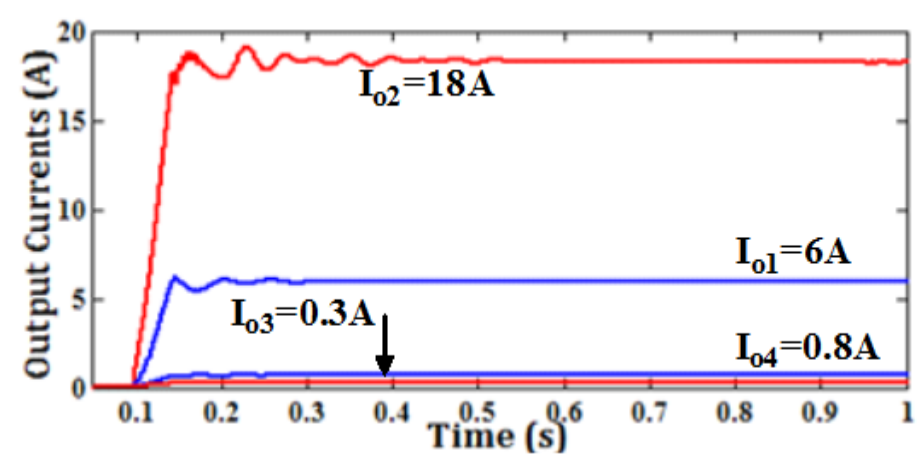

(b)

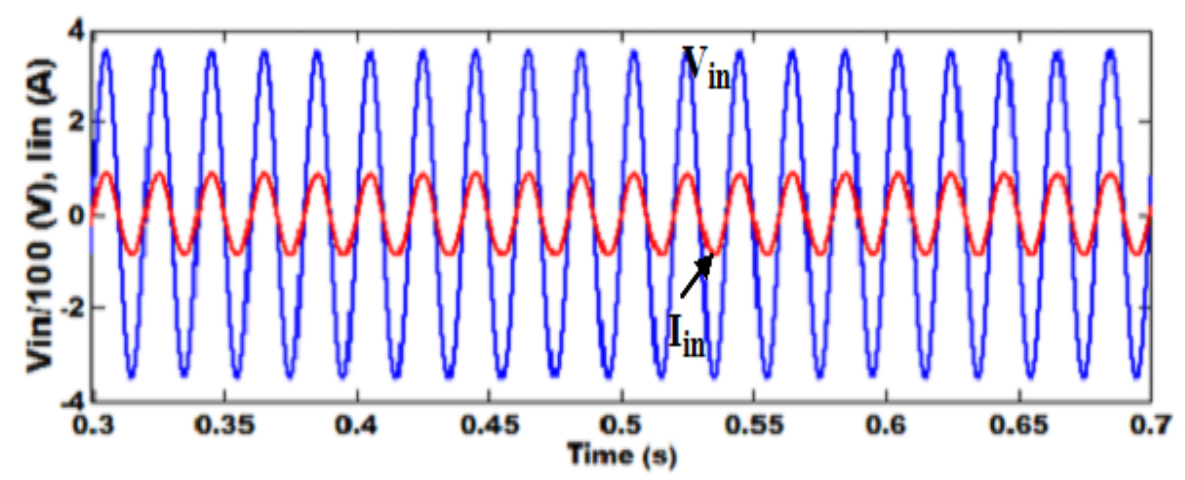

(c)

Figure 4. Waveforms of BBC at supply voltage $250 \mathrm{~V}$. (a) $\mathrm{V}_{01^{-}} \mathrm{V}_{04}(\mathrm{~V})$, (b) $\mathrm{I}_{01}-\mathrm{I}_{04}$ (A) and (c) $\mathrm{V}_{\text {in }} / 100$ (V) and $\mathrm{I}_{\text {in }}(\mathrm{A})$

\subsection{MOSMPS with decreased supply voltage $\mathrm{Vin}=170 \mathrm{~V}$ and rated load}

The waveforms of regulated multiple output voltages, output currents, supply voltage and current at $\mathrm{V}_{\mathrm{in}}=170 \mathrm{~V}$ are depicted in Figure 5. It is concluded from the waveforms that $\mathrm{V}_{\mathrm{o} 1}$ to $\mathrm{V}_{\mathrm{o} 4}$ are regulated well by the $\mathrm{NN}$ controller. $\mathrm{V}_{\text {in }}$ and $\mathrm{I}_{\text {in }}$ waveforms prove that supply current drawn is maintained sinusoidal and in phase with the source voltage to maintain the PF nearly unity. The values of DF, DPF and PF achieved with NN controller are $0.998,1$ and 0.998 respectively. The THD of $\mathrm{I}_{\text {in }}$ is $2.2 \%$ and adheres to the limit suggested by IEC 61000-3-2 standard. BBC based SMPS when simulated with conventional controller, reduces the THD of the source current to $4.6 \%$ and the PF at the supply side is maintained at 0.96 . 


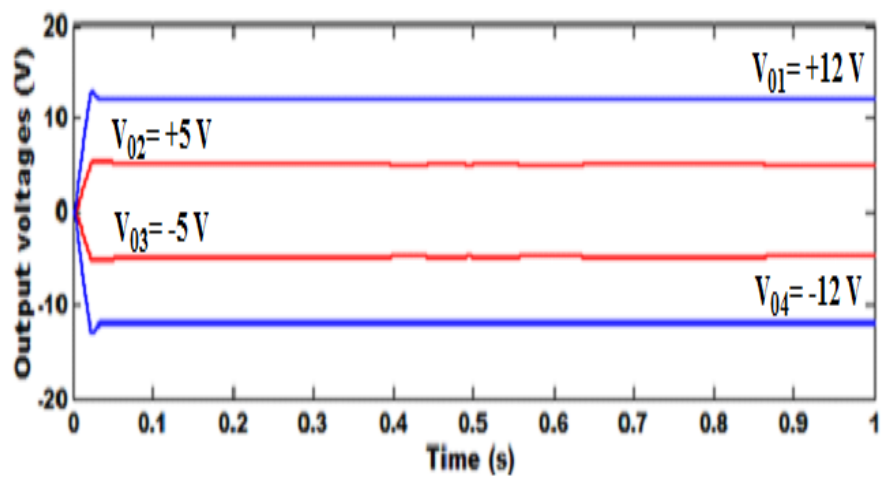

(a)

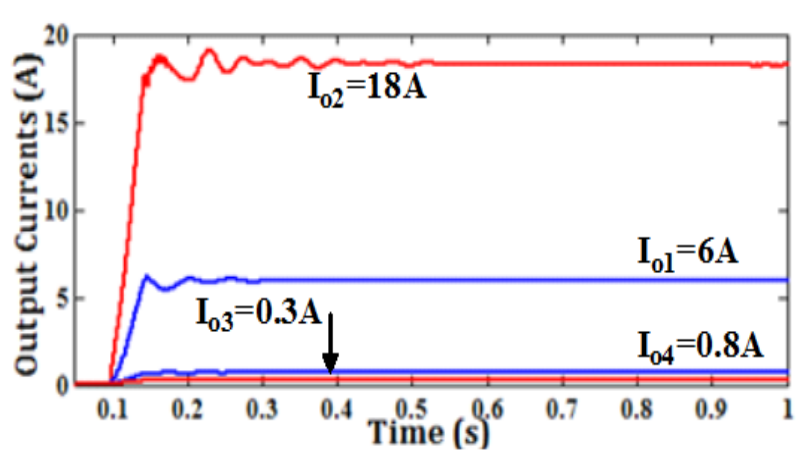

(b)

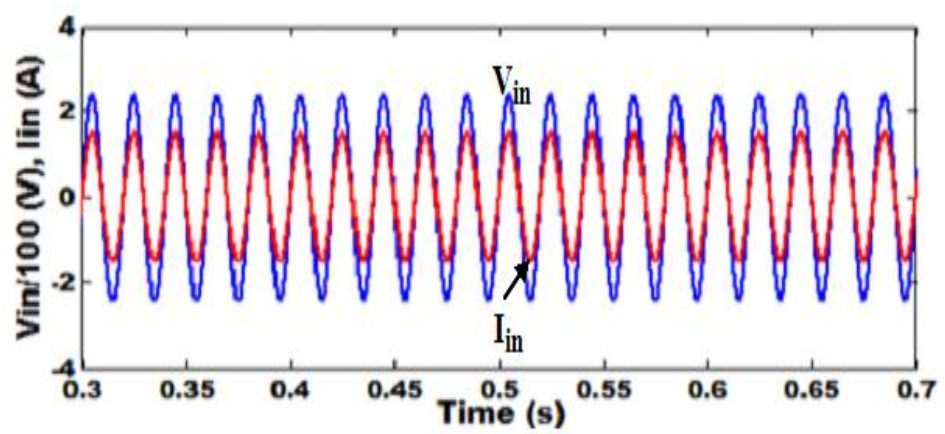

(c)

Figure 5. Waveforms of BBC at supply voltage $170 \mathrm{~V}$. (a) $\mathrm{V}_{01^{-}}-\mathrm{V}_{04}(\mathrm{~V})$, (b) $\mathrm{I}_{01^{-}} \mathrm{I}_{04}$ (A) and (c) $\mathrm{V}_{\text {in }} / 100$ (V) and $\mathrm{I}_{\text {in }}(\mathrm{A})$

\subsection{MOSMPS with rated supply voltage and load variation}

The waveforms of regulated multiple output voltages, output currents, supply voltage and current at $\mathrm{V}_{\text {in }}=220 \mathrm{~V}$ are depicted in Figure 6. It is concluded from the waveforms that $\mathrm{V}_{\mathrm{o} 1}$ to $\mathrm{V}_{\mathrm{o} 4}$ are regulated well by the NN controller even under load variation at terminal 2 from $50 \%$ to $100 \%$ at $0.5 \mathrm{~s}$. The $\mathrm{I}_{\mathrm{o} 2}$ waveform shows the load variation at terminal 2 from $50 \%$ to $100 \%$ at $0.5 \mathrm{~s}$. $\mathrm{V}_{\text {in }}$ and $\mathrm{I}_{\text {in }}$ waveforms prove that supply current drawn is maintained sinusoidal and in phase with the source voltage to maintain the PF nearly unity. The values of DF, DPF and PF achieved with NN controller are $0.981,1$ and 0.981 respectively. The THD of $\mathrm{I}_{\text {in }}$ is $3.4 \%$ and adheres to the limit suggested by IEC 61000-3-2 standard. BBC based SMPS when simulated with conventional controller, reduces the THD of the source current to $5.6 \%$ and the PF at the supply side is maintained at 0.9 . 


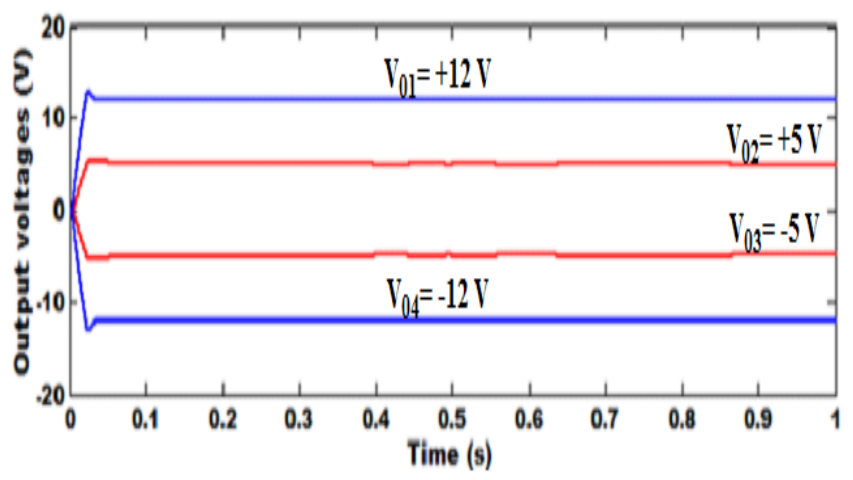

(a)

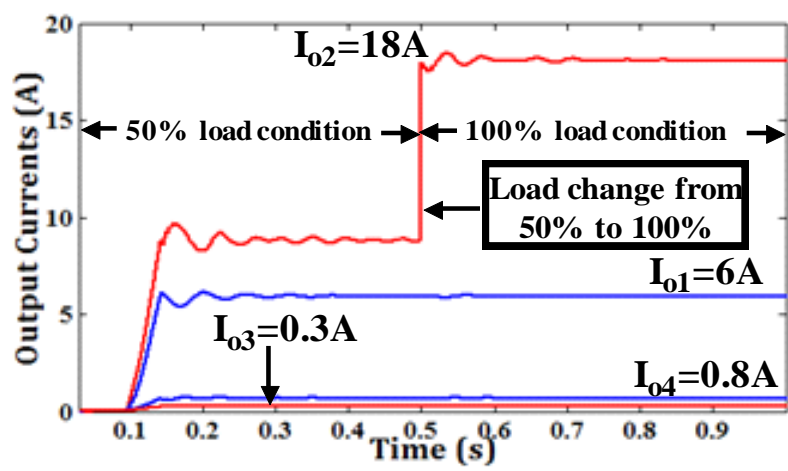

(b)

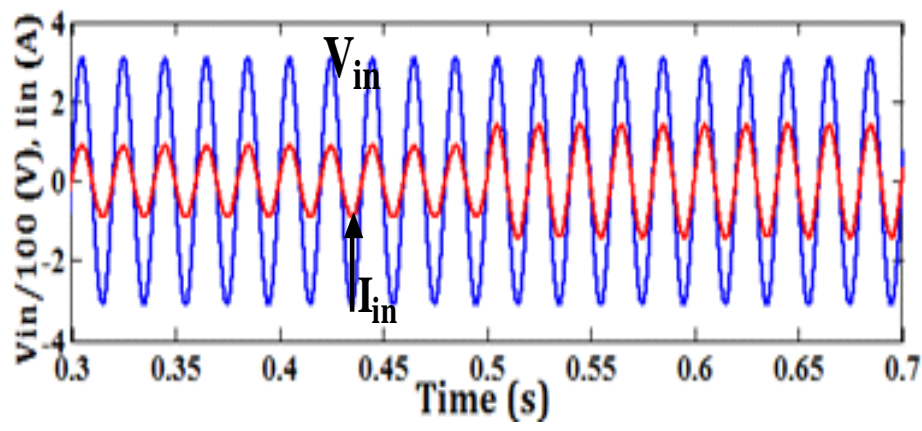

(c)

Figure 6. Waveforms of $\mathrm{BBC}$ at rated supply voltage and load variation at $\mathrm{V}_{\mathrm{o} 2}$. (a) $\mathrm{V}_{01}-\mathrm{V}_{04}(\mathrm{~V})$, (b) $\mathrm{I}_{01}-\mathrm{I}_{04}(\mathrm{~A})$ and (c) $\mathrm{V}_{\text {in }} / 100(\mathrm{~V})$ and $\mathrm{I}_{\text {in }}(\mathrm{A})$

The simulation results of $\mathrm{BBC}$ with $\mathrm{NN}$ and conventional controller are tabulated in Table 2 and Table 3. NN controlled BBC based SMPS takes $0.18 \mathrm{~s}$ to attain steady state and the \% overshoot of $\mathrm{V}_{\mathrm{o} 1}$ is 1.90 during transient response. It is verified from the tabulation that the MOSMPS with NN controller has superior performance when compared to conventional controller in terms of voltage regulation and PQ improvement. Figure 7 shows the comparison of input power factor of MOSMPS with NN and conventional controller for various source voltage conditions. Figure 8 depicts the comparison of THD of source current drawn by the MOSMPS at different supply voltages. Simulation results tabulated in Table 2 and Table 3 and Comparison chart shown in Figure 7, Figure 8 and Figure 9 highlight the performance of NN controlled MOSMPS when compared to conventional controller. NN controller performs better in, maintaining the PF close to unity, reducing the THD of source current and regulating the output voltages. Figure 9 gives the 
comparison of overshoot and undershoot of $\mathrm{V}_{\mathrm{o} 1}$ at $\mathrm{V}_{\mathrm{in}}=220 \mathrm{~V}$ with conventional and NN controller. It proves that the transient response of MOSMPS is better with NN controller.

Table 2. Parameter Values of MOSMPS under Different Source Voltage and Load Conditions

\begin{tabular}{|c|c|c|c|c|c|c|c|c|c|c|c|c|c|c|}
\hline & \multirow[b]{2}{*}{$\mathrm{DF}$} & \multirow[b]{2}{*}{ DPF } & \multicolumn{2}{|c|}{$\mathrm{PF}$} & \multirow{2}{*}{\multicolumn{2}{|c|}{$\begin{array}{c}\% \text { THD } \\
\text { of } \mathrm{I}_{\text {in }}\end{array}$}} & \multicolumn{4}{|c|}{$\begin{array}{c}\text { \%Output voltage ripple } \\
1 \%\end{array}$} & \multicolumn{4}{|c|}{$\begin{array}{c}\% \text { Output voltage ripple } \\
2 *\end{array}$} \\
\hline & & & $1^{*}$ & $2 *$ & $1 *$ & & $\mathrm{~V}_{01}$ & $\mathrm{~V}_{02}$ & $\mathrm{~V}_{03}$ & $\mathrm{~V}_{04}$ & $V_{01}$ & $\mathrm{~V}_{02}$ & $\mathrm{~V}_{03}$ & $\mathrm{~V}_{04}$ \\
\hline \multicolumn{15}{|c|}{ Performance at $100 \%$ load } \\
\hline 170 & 0.998 & 1 & 0.998 & 0.96 & 2.2 & 4.6 & & & & & & & & \\
\hline 220 & 0.996 & 1 & 0.996 & 0.94 & 2.35 & 5.1 & 1.4 & 1.8 & 2.1 & 2.0 & 1.8 & 2.3 & 2.7 & 2.8 \\
\hline 250 & 0.995 & 1 & 0.995 & 0.90 & 3.42 & 5.4 & & & & & & & & \\
\hline \multicolumn{15}{|c|}{ Performance at $50 \%$ load } \\
\hline 220 & 0.981 & 1 & 0.981 & 0.9 & 3.4 & 5.6 & 1.6 & 1.9 & 2.3 & 2.1 & 1.9 & 2.3 & 2.8 & 2.9 \\
\hline
\end{tabular}

Table 3. Comparison of Performance of MOSMPS at full load with NN and Conventional Controllers

\begin{tabular}{|c|c|c|c|c|c|}
\hline \multicolumn{2}{|c|}{ Settling time (s) } & \multicolumn{2}{|c|}{$\begin{array}{c}\text { Transient response of } \mathrm{V}_{\mathrm{ol} 1} \text { with } \mathrm{NN} \\
\text { control }\end{array}$} & \multicolumn{2}{|c|}{$\begin{array}{l}\text { Transient response of } \mathrm{V}_{\mathrm{ol}} \text { with } \\
\text { conventional control }\end{array}$} \\
\hline $\begin{array}{c}\mathrm{NN} \text { control } \\
0.18\end{array}$ & $\begin{array}{c}\text { Conventional control } \\
0.23\end{array}$ & $\begin{array}{c}\text { \%Overshoot } \\
1.90\end{array}$ & $\begin{array}{l}\text { \%Undershoot } \\
2.00\end{array}$ & $\begin{array}{l}\text { \%Overshoot } \\
3.26\end{array}$ & $\begin{array}{c}\text { \%Undershoot } \\
3.42\end{array}$ \\
\hline
\end{tabular}

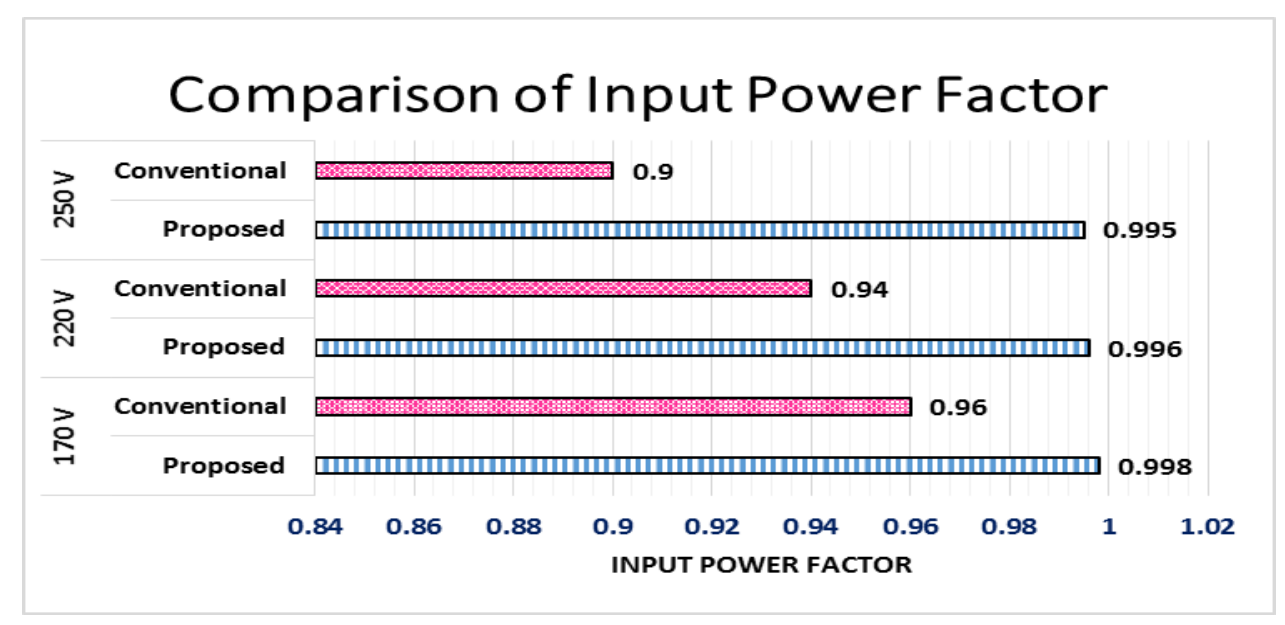

Figure 7. Comparison of input power factor

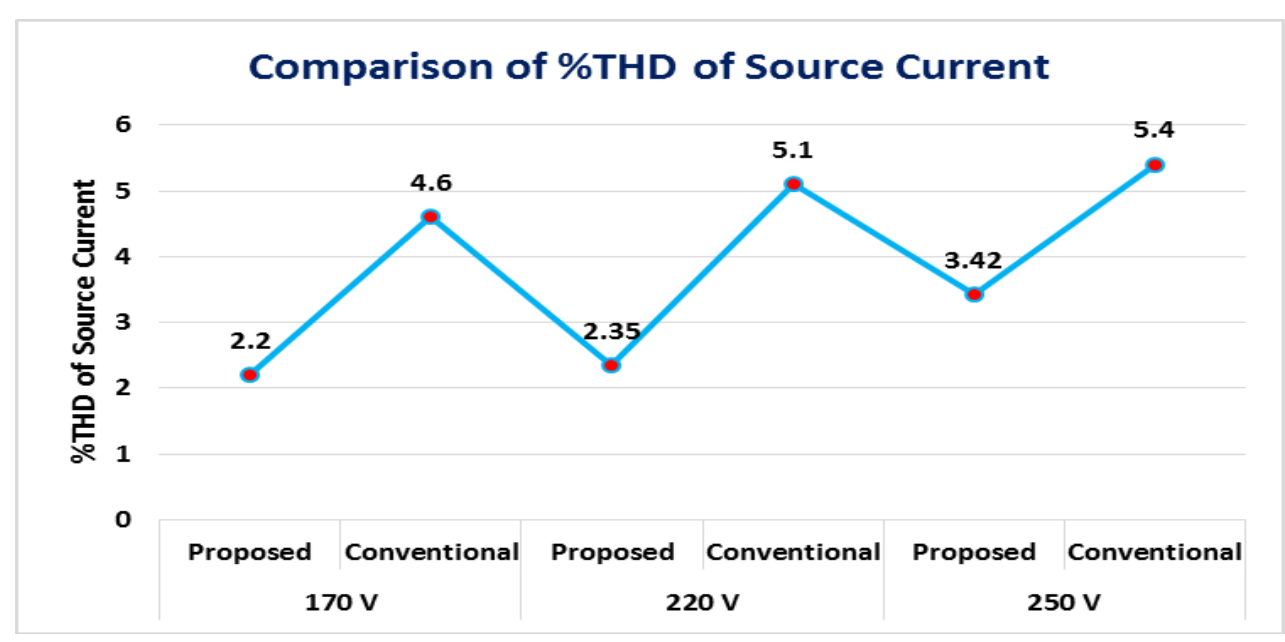

Figure 8. Comparison of THD of source current 


\section{Comparison of \%Overshoot and Undershoot at $100 \%$ Load}

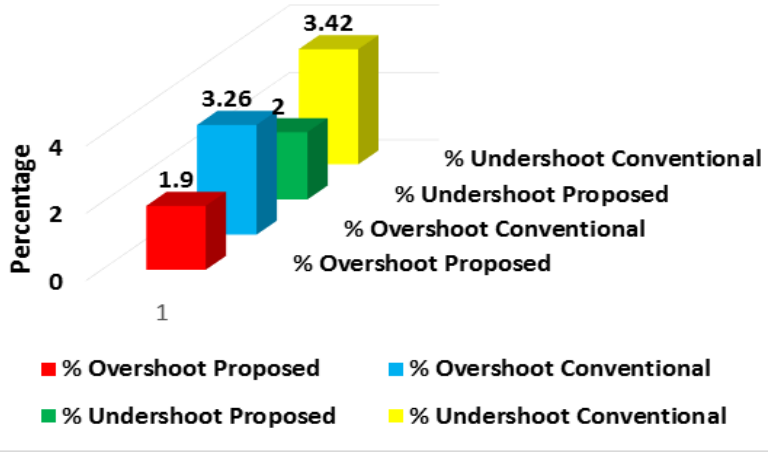

Figure 9. Comparison of overshoot and undershoot of $\mathrm{V}_{\mathrm{o} 1}$ at $\mathrm{V}_{\text {in }}=220 \mathrm{~V}$

\section{CONCLUSION}

A $175 \mathrm{~W}$ rated MOSMPS is designed, modeled and implemented with a NN controlled two stage buck boost converter in MATLAB Simulink software. The MOSMPS is analyzed with NN and conventional controller in terms of THD of $\mathrm{I}_{\mathrm{in}}$, input power factor, output voltage ripple, overshoot, undershoot and settling time under steady state and fluctuating conditions. Simulation results and tabulated performance prove that $\mathrm{NN}$ controller is superior to conventional control under fluctuating conditions. As the THD of supply current and PF at the input side meet the IEEE standard of power quality, the NN controlled BBC based MOSMPS is best suited for PC power supply application.

\section{REFERENCES}

[1] Shika Singh, Bhim Singh, G.Bhuvaneswari, Vashist Bist, Ambrish Chandra and Kamal Al-Haddad, "Improved Power Quality Bridgeless Converter based Multiple Output SMPS,” IEEE Trans. Industry Application, vol. 51, no. 1, pp. 721-732, Jan/Feb. 2015.

[2] Limits of Harmonic Current Emissions, International Electro Technical Commission Standard, 61000-3-2, 2004.

[3] S. Malathi, J. Jayachandran, "Neural Network based pqr theory for harmonic reduction and neutral current mitigation," International Journal of Electrical and Computer Engineering, vol. 8, no. 2, pp. 825-836, April 2018.

[4] J. Chen, D. Maksimovic, and R. W. Erickson, "Analysis and design of a low-stress buck-boost converter in universal-input PFC applications," IEEE Trans. Power Electron., vol. 21, no. 2, pp. 320-329, Mar. 2006.

[5] A. Abramovitz and K. M. Smedley, "Analysis and Design of a Tapped Inductor buck-boost PFC Rectifier with Low Bus Voltage," IEEE Trans. Power Electron., vol. 26, no. 9, pp. 2637-2649, Sep. 2011.

[6] B. Zhao, A. Abramovitz, and K. Smedley, "Family of Bridgeless Buck Boost PFC Rectifiers," IEEE Trans. Power Electron., vol. 30, no. 12, pp. 6524-6527, Dec. 2015.

[7] M. Bodetto, A. El Aroudi, A. Cid-Pastor, J. Calvente, and L. Martinez-Salamero, "Design of AC-DC PFC high order Converter with Regulated Output Current for Low Power Applications," IEEE Trans. Power Electron., vol. 31, no. 3, pp. 2012-2025, Mar. 2016.

[8] Singh, S. Singh, A. Chandra and K. Al-Haddad, "Comprehensive study of single phase AC-DC power factor corrected converters with high frequency isolation," IEEE Trans. Industrial Informatics, vol. 7, no. 4, pp. 540-556, Nov. 2011.

[9] M.S Jayakumar, Ajeesh G, “A High Efficient High Input Power Factor Interleaved Boost Converter," International Journal of Electrical and Computer Engineering, vol. 2, no. 3, pp. 339-344, June 2012.

[10] Ganesh S, Chiranjit Ghosh T, Kokilasree R, Nandhakumar M and Md Haroon Alim T, "DC UPS for Critical Loads," International Journal of Electrical and Computer Engineering (IJECE), vol. 5, no. 2, pp. 231-242, April 2015.

[11] J. Jayachandran and R. Murali Sachithanandam, "Performance Investigation of Artificial Intelligence based Controller for Three Phase four Leg Shunt Active Filter," Frontier in Energy, vol. 9, no. 4, pp. 446-460, 2015.

[12] J.J ayachandran and R. Murali Sachithanandam, "Neural Network-Based Control Algorithm for DSTATCOM Under Non ideal Source Voltage and Varying Load Conditions," Canadian Journal of Electrical and Computer Engineering, vol. 38 no. 4, pp. 307-317, Fall 2015.

[13] Shikha Singh,Bhim Singh and G. Bhuvaneswari, "Improved Power Quality Switched-mode Power Supply using buck-boost Converter," IEEE Transactions on Industrial Applications, vol. 52, no. 6, pp. 5194-5202, December 2016. 
[14] Adrian Ioinovici, "Power Electronics and Energy Conversion Systems," vol. 1, Fundamentals and Hard- switching Converters, $1^{\text {st }}$ ed. John Wiley \& Sons, Ltd., 2013.

Figure Legends:

Figure 1 Circuit configuration of two-stage MOSMPS employing buck-boost PFC converter

Figure 2 Modes of BBC in DCM.

Figure 3 Waveforms of $\mathrm{BBC}$ at rated supply voltage.

Figure 4 Waveforms of BBC at supply voltage $250 \mathrm{~V}$

Figure 56 Waveforms of BBC at supply voltage $170 \mathrm{~V}$

Figure 6 Waveforms of $\mathrm{BBC}$ at rated supply voltage and load variation at Vo2

Figure 7 Comparison of input power factor

Figure 8 Comparison of THD of source current

Figure 9 Comparison of overshoot and undershoot of Vol at Vin $=220 \mathrm{~V}$

Table Legends:

Table 1. Parameters of MOSMPS

Table 2. Parameter values of two stage buck boost converter based MOSMPS under different source voltage and load conditions

Table 3. Comparison of performance of two stage buck boost converter based MOSMPS at full load with NN and conventional controllers

\section{BIOGRAPHIES OF AUTHORS}

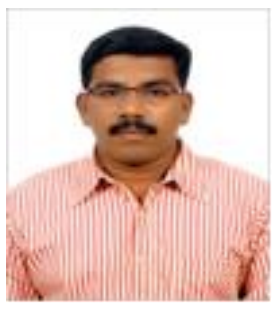

J. Jayachandran was born in India. He received the B.E. degree in Electrrical and Electronics Engineering from Kongu Engineering college, Tamilnadu in 1999 and M.E. degree in Power Electronics and drives from Bharathidasan University, Thanjavur Tamilnadu in 2000. Presently Pursuing Ph.D. in the area of Power Electronics at SASTRA University, Thanjavur, India. His area of interest are Power Quality, Power Converters and Renewable Energy Sources.

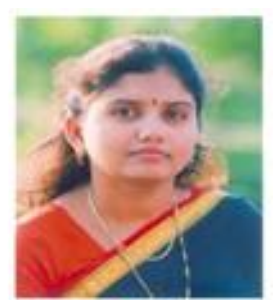

S. Malathi was born in India. She received the B.E. degree in Electrical and Electronics Engineering from Bharathidasan University, Tamilnadu in 2000 and M.Tech. degree in Power Electronics and Drives from SASTRA University, Thanjavur Tamilnadu in 2004. Presently Pursuing Ph.D. in the area of Power Electronics at SASTRA University, Thanjavur, India. Her area of interest are Power Converters and power quality. 